\title{
Detection of Fungicide Resistance
}

\author{
Janna L. Beckerman
}

Additional information is available at the end of the chapter

http://dx.doi.org/10.5772/55981

\section{Introduction}

Fungicide resistance is a form of selection that describes a fungus's ability to survive and reproduce in the presence of a fungicide ${ }^{1}$. Practical resistance (field resistance) results when the prevalence of fungicide resistant isolates reaches a critical threshold where disease control is no longer observed. The primary factors that select for fungicide resistance in an organism are:

i. the biology of the pathogen,

ii. the mechanism(s) of action of the fungicide,

iii. the rate and frequency of fungicide application.

It is important to note that most fungi show a broad range of sensitivities to the spectrum of different fungicides. For example, most fungicides for the control of Chromista (e.g., mefenoxam, fluopicolide, dimethomorph) do not control true fungi; some fungicides are specific for ascomycete (e.g., thiophanate-methyl) or basidiomycete fungi (flutolanil), and species within the same genus of fungi may respond differently to certain fungicides (Leroux et al. 2012). Additionally, different genotypes exist within a spectrum of sensitive to resistant (Albertini et al. 1999). The relationship between the frequency of fungicide application and resistance has been established (King and Griffin, 1985; Suzuki et al. 2010), and the role of rate or dose in this process is deserving of further study (Genet et al. 2006; van den Bosche et al. 2011).

In 2006, the world market consumed approximately 520 million pounds of fungicide (Grube et al. 2011), a number that is expected to increase as the consumption of other pesticides declines (Troy, 2011). The discovery, development, and registration of a new pesticide comes at a cost (not including the capital costs or production). In 2006, this price was

${ }^{1}$ Due to issues of length, brevity and complexity, this review will only deal with fungicides that are for the control of true fungi, and not fungicides for the management of Chromista. 
estimated to exceed $\$ 180$ million (Whitford et al. 2006). With fewer fungicides available (particularly with new modes of action) and increasing consumption, risk of fungicide resistance is even greater, and failures will more profoundly impact cropping systems. All of these factors increase the need for rapid detection of fungicide resistance. Historically, the detection of fungicide resistance in the field has been difficult because disease control failures can be caused by factors other than resistance, including improper fungicide selection, improper timing, reduction of recommended rate, and erroneous sprayer calibration (Latin, 2011).

Rarely, are molecular proofs of fungicide resistance ever fulfilled with plant pathogenic fungi, although many of the genes involved in fungicide resistance are studied in model systems to elucidate mechanisms (Zhang et al. 2002). Usually, resistant individuals are detected using bioassays (sensitivity tests or poison plate assays) and those resistant isolates may be correlated with molecular markers, many of which are based upon previous studies (Koernraadt et al. 1992; Albertini et al. 1999; Schnabel and Jones, 1991; Lesniak et al. 2011). In some instances, segregation analysis between crosses of sensitive and resistance phenotypes is often used to strengthen this correlation (Faretra and Pollastro 1993; Orth et al. 1995; Dyer et al., 2000); however, the ultimate mechanism of resistance is often lacking. Ultimately, the success of molecular detection is only useful if the expected genetic profile that is being screened correlates to the phenotype of resistance. Laboratory tests are required to determine the level of resistance in numerous suspect isolates of the pathogen before an assessment of the status of the orchard, plantation, vineyard or field can be determined. Traditionally, this meant direct-plating of single-spore isolates or mycelial plugs on medium amended with various concentrations of fungicides under specified growth conditions, and then determining inhibition of growth and/or spore germination (Koller et al. 1997). Many fungi, including the economically important downy mildews, powdery mildews, and rust, cannot be cultured. Other fungi, like Venturia inaequalis, grow slowly in culture, taking at least four weeks to obtain results, which, when achieved, are no longer useful for in-season disease management recommendations (Chapman et al. 2011, and others). Unfortunately, the phenotypic comparison of fungicide resistance can be inconsistent due to media choice (Cox et al. 2009; Rampersad 2011), choice of active ingredient (technical grade versus field fungicide), degradation of material, stability of resistance (Zhu et al. 2012; Cox et al. 2007), and genetic background of isolates. One method of circumventing this inconsistency is through the direct testing of genotype, which has resulted in an emerging paradigm of nucleic acid-based detection systems for the rapid identification of fungicide resistance.

Molecular methods have the potential to provide a more rapid and reliable assessment of fungicide resistance, and there are many examples of the successful use of these methods in applied plant pathology (for a review, see Vincelli and Tisserat, 2008). Genetic testing of potentially resistant isolates can be performed directly from disease lesions, obviating the need for isolation, and subsequent growth of the fungus in vitro (Quello et al. 2009; others). Furthermore, molecular methods characterize genotype, not phenotypic expression under laboratory conditions. This is particularly important in the case of recalcitrant fungal 
pathogens, like $V$. inaequalisor Mycosphaerella fijiensis and obligate pathogens such as Blumeria and Plasmopara. In the case of obligate pathogens in particular, genotype can be readily identified long before phenotype can be determined due to the slow growth of the organism.

As a paradigm, nucleic acid-based detection systems offer rapid (within hours) and sensitive (to picograms) methods to detect the presence of alleles known to confer resistance. First used by Koenraadt et al. (1992b) to detect benomyl resistance in $V$. inaequalis, a variety of sensitive and sophisticated nucleic acid-based detection systems have since been developed and promoted to identify resistance.

However, it is impossible to review the developing paradigm and not question how we implement these detection systems to provide the end-user, in this instance, the farmer, with the information necessary to make the appropriate management decision. The objective of this review is to briefly discuss the current fundamental approaches of nucleic acid based systems, and the currently known targets for the molecular detection of fungicide resistance. The paper concludes with the limitation of these techniques, the impact detection has had on the management of fungicide resistance, and future directions.

\section{Nucleic acid based detection techniques}

The molecular detection of fungicide resistance can be boiled down into three fundamental techniques: Hybridization, amplification, and sequencing. It is important to stress though, that most amplification technologies used today are also partly based on hybridization technology, and that all sequencing technology is based upon amplification. This article is not designed to review the preponderance of available techniques; for that information, the reader is encouraged to review the current literature, as new application technologies are produced every year. Instead, this article focuses on certain paradigms that have developed between laboratories for the detection of fungicide resistance, and to provide both structure and context as to where we are currently positioned.

\section{Hybridization}

Hybridization is one of the oldest molecular techniques: Sample DNA is denatured into single strands and allowed to anneal with a single-stranded probe labeled with some type of signal (radioactive isotopes, antibodies, enzymes or chemiluminescent compounds) to permit detection. Target DNA is bound to solid support (historically nitrocellulose then nylon, although today numerous substrates are available, including magnetic beads and polystyrene microspheres). Direct hybridization is the simplest assay for single nucleotide discrimination. For 15 to 20-base oligonucleotides, the approximate melting temperature for hybridization of a perfectly matched template compared to one with a single base mismatch can differ by several degrees (Ikuta et al. 1987) - a fact that can be exploited to create a variety of multiplex detection techniques, and discriminate within samples or between samples to a single nucleotide polymorphism. 


\section{Amplification}

Briefly, polymerase chain reaction (PCR) is the basis for all amplification-type reactions and involves the heating of the sample DNA for denaturing, followed by the annealing of the small, oligonucleotides that serve as primers for DNA polymerase, followed by the extension of the primers by a thermostable, DNA polymerase. Numerous books and laboratory manuals exist as references for PCR operation and optimization (Sambrook et al, 1989). PCR based detection of fungicide resistance depends upon the ability of the reaction to selectively amplify specific regions of DNA, and usually require several post-PCR steps, including agarose gel electrophoresis for either confirmation of amplicon presence or size, or restriction enzyme analysis (Lesniak et al. 2011; Fontaine et al. 2009; Quello et al. 2009; and reviewed by Ma and Michailides 2005). The development of new fluorescent techniques (LAMP, etc) has led to novel assay formats that greatly simplify the protocols used for the detection of specific nucleic acid sequences (Nurmi et al 2000) and allow for the detection of a specific PCR product in a homogeneous solution without the need to open the amplification tubes after PCR or gel electrophoresis (Tomlinson et al. 2012). In these techniques and their variations, PCR products are monitored as they are generated during the course of the reaction via one of two ways: By fluorescent or chemiluminescent dyes that bind to double-stranded DNA in a nonspecific fashion, or by fluorescence-labeled probes that bind to specific sequences. As a result, PCR amplification, amplicon detection and analysis are all achieved in a single reaction (Figure 1). If this is not enough detection power, multiple, sequence-specific probes with unique fluorescent reporters can be added to the reaction, allowing for additional, and simultaneous, determination of multiple products. Techniques such as this are ideally suited for the detection of fungicide resistance, particularly if multiple alleles are involved. Furthermore, the results can be read in real time as the PCR product accumulates or at the end of the thermal cycling protocol directly from the amplification wells. Although many scientists believe that the choice between real time or "standard" PCR (and gel electrophoresis) depends on whether a quantitative or qualitative assay is desired (Nurmi et al. 2000), the reality is that equipment expense and laboratory expertise limits most "applied" labs, resulting in a preponderance of scientifically dazzling techniques that may be used in a human clinical setting, or a plant pathology laboratory focused on basic science, but are rarely, if ever, subsequently tested using isolates from a field failure.

\section{Hybrid technologies}

Technologies such as Luminex Xmap powerfully combine hybridization and PCR to create a technique that is capable of discriminating and reporting up to 500 different reactions in a single reaction vessel in just a few seconds per sample (Dunbar 2005; Luminex 2011). The approximate melting temperature for 15 to 20-base oligonucleotides can differ by several degrees compared to a "perfectly matched" hybridization (Ikuta et al. 1987). By exploiting and combining this discriminatory hybridization temperature with PCR and microarrays systems and digital imaging, the user can screen up to several hundred thousands of DNA probes (either PCR products or synthetic oligonucleotides) per square centimeter of a solid matrix. Multiple readings per beadset provide built-in internal controls (Luminex 2011). For 
medically relevant human pathogens, whole genome arrays have been developed; it is hardly a stretch to imagine development of arrays for a few dozen alleles for important genes, or even genes important for fungicide resistance. Although financially out of reach for most labs, few could envision the sequencing of entire genomes for a few thousand dollars as we do today, and it is hopefully only a matter of time before microarrays to detect fungicide resistance in agriculturally important crops are widely available. Today, and certainly for the next few years, both cost and accessibility also remain obstacles to the development of such arrays. Within reason and immediate reach is a 96-well format that provides fast, simple, and highly reproducible analyses of up to 96 PCR products - which still translates into an assortment of alleles for a variety of fungicide resistance genes.

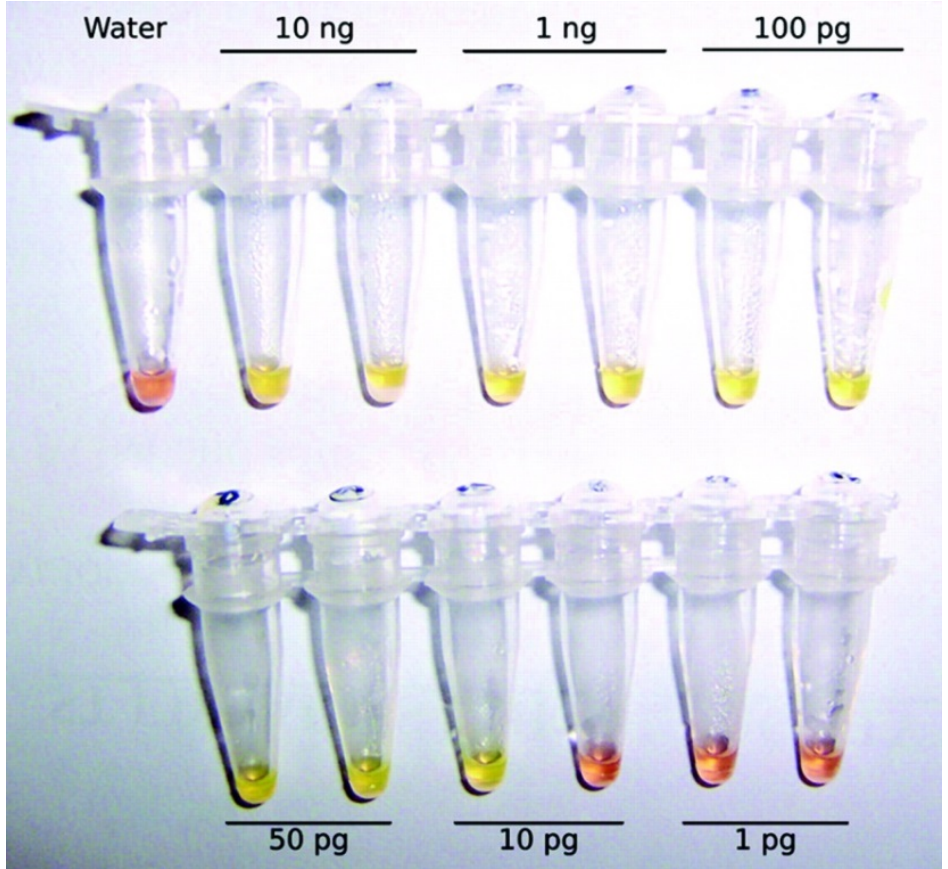

Figure 1. LAMP technologies have been used to detect the presence of invasive species, like Phytophthora ramorum. The presence of LAMP product in positive reaction mixtures causes a color change from orange to yellow. In time, this technology could be used to detect some type of fungicide resistance in the field. Photo from Tomlinson et al. 2007.

For most, smaller laboratories, a more realistic approach concerns the use of polymerase chain reaction coupled with cleaved amplified polymorphic sequences (PCR-CAPS). Restriction-fragment length polymorphisms due to small nucleotide polymorphisms (SNP) that co-segregate or are caused by fungicide resistance create or abolish restriction sites in PCR products, and can be exploited for detection of fungicide resistance through the careful selection of locus-specific oligonucleotide primers (Banno et al. 2008; Lesemann et al. 2007, Quello et al. 2009, Fontaine et al. 2009; others). 
Assuming that a SNP is present and can be used, oligonucleotide primers with unique sequences are used to amplify a defined locus, followed by the use of a restriction enzyme that can discriminate between resistant and sensitive isolates (Figure 2). An alternative to PCR-CAPS is allele specific (AS-PCR), in which the mutation that confers resistance is used to design primers that specifically amplify the mutated allele, but not the wild-type one (Fontaine et al. 2009, Lesniak et al. 2011, others). This approach is more sensitive, and does not require a RFLP to detect resistance, but also does not detect any heteroplasmy or heterozygosity.

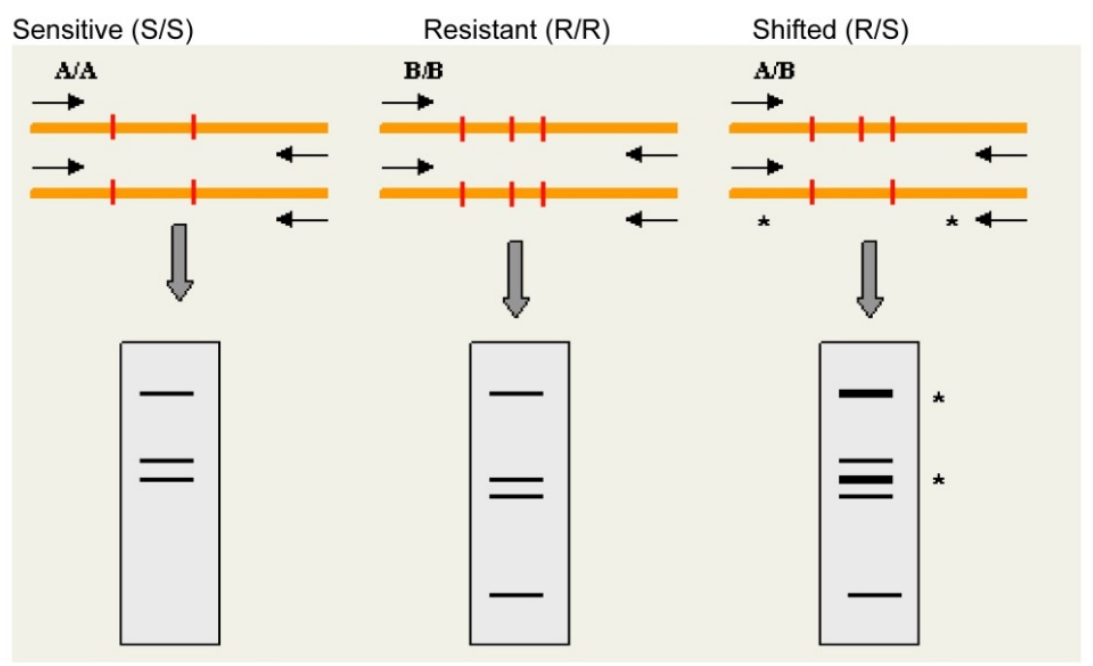

Figure 2. Cleaved Amplified Polymorphic Sequences (CAPS) polymorphisms result from single nucleotide polymorphisms (SNPS), insertions or deletions (INDELS) that create or destroy restriction enzyme recognition sites in polymerase chain reaction (PCR) amplicons. For example, three isolates have different level of fungicide resistance to azoxystrobin: Sensitive $S$ and Resistant $R$, and shifted (moderately resistant) from the isolate with mitochondrial heteroplasmy R/S. The amplified fragments from $S$ and $R$ contain two and three $R E$ recognition sites, respectively, which is sufficient discrimination in the case of fungi, which are mostly haploid. (Sierotzki et al. 2000; Avenot and Michailides, 2010). This can also result in the identification of heteroplasmy in resistance (as seen in Fontaine et al., 2009) with restriction patterns that resemble those found in heterozygous diploids, or even incomplete digestions. When fractionated by agarose or acrylamide gel electrophoresis, the PCR products digested by the RE will give readily distinguishable patterns. Image from http://www.ncbi.nlm.nih.gov/projects/genome/probe/doc/TechCAPS.shtml

\section{DNA sequencing}

DNA sequencing, as performed for the last 30 years, has been done via the Sanger method and is the most commonly used sequencing technique available. Genome-sequencing efforts have resulted in technological advances in DNA sequencing and led to the improvement of longer sequencing length, done faster and with less expense. It has also permitted the rapid sequencing of isolates (in part or into total) that did not conform to expected genotype: 
phenotype relationships (Lesniak et al. 2011; Quello et al. 2010;Leroux et al. 1999, and many others).

Metzker (2009) provides an excellent review of 'next generation sequencing' technology, although the rapid pace of technology marches on. One of the newer sequencing technologies that have immediate application to the detection of fungicide resistance is pyrosequencing. DNA pyrosequencing, a method of sequencing by synthesis, was first introduced in 1996, and is faster and less expensive than traditional Sanger (dideoxy sequencing) DNA sequencing methodologies. Unlike the Sanger method, DNA pyrosequencing utilize a cascade of enzymatic reactions that yield detectable light proportional to incorporated nucleotides. As a result, pyrosequencing yields relatively short read lengths and limited amounts of sequence data per pathogen or microbe. However, with careful target selection and primer placement, DNA pyrosequencing has been used for genotyping, SNP detection, and identification of microbes (Petrosino et al. 2009). Most importantly, pyrosequencing has been used to detect point mutations in antimicrobial resistance genes as a means of molecular resistance testing, including antifungal resistance in clinically important fungi (Wiederhold et al. 2008).

Pyrosequencing offers comparable accuracy to conventional DNA sequencing via the Sanger method, but provides greater opportunity for large sample numbers to be processed in parallel. The reaction is performed in real-time, obviating the need for electrophoresis, labeled nucleotides and primers. This is a technique that can be multiplexed, which economically enables rapid and accurate screening of a large number of samples, however, the prohibitive cost of equipment [\$200,000-\$1million per machine (Metzker 2009)], and technical expertise limits the use of this technology to research universities and industry.

Finally, a review of the variety of molecular techniques used for diagnostic applications (and the constant development of 'new' techniques) demonstrates that no universal technique exists which is optimal for detection of nucleic acids. The choice of a particular technique is also dependent on the information required, the targets under consideration, and obviously, cost. Regardless of any given or "popular" technique, new techniques continue to be developed which involve new approaches to amplification, hybridization, formats, imaging, and labels.

\section{Detection of fungicide resistance}

Regardless of the techniques used, the primary targets of fungicide activity (and thus fungicide resistance) have remained remarkably constant, and include mitosis and cell division; sterol biosynthesis; respiration; nucleic acid synthesis; and signal transduction. The widespread use of fungicides has also resulted in resistance in non-target genes, namely drug transporters, which are included in this review due to the role they play in fungicide resistance. The mechanisms of fungicide resistance that have been identified to date, include: i) a mutation in the target site of the antimicrobial agent that reduces the binding of the fungicide; ii) overproduction of the gene that is the target of the fungicide; (iii) reduced uptake of the antimicrobial agent, and (iv) active efflux of the fungicide. Other mechanisms 
that may have roles in fungicide resistance (based upon host-pathogen interactions, or basic fungal and other microbe biology) include, the possible presence of an enzyme that inactivates the antimicrobial agent (e.g., pisatin-pisatin demethylase) or even mutations that result in the posttranscriptional or posttranslational modification of the target enzyme or other regulatory factor (Mann and Jenson, 2003), resulting in reduced binding of the antimicrobial. Resistance may also be caused by unrecognized mechanisms - a problem for scientists trying to understand mefenoxam, phosphorous acid, or dodine resistance, to name a few of the fungicides where resistance is known, but the primary mechanism of resistance has not yet been identified.

\subsection{Mitosis and cell division: Beta-tubulin assembly inhibitors}

Introduced in the 1960s, benzimidazoles were the first penetrant fungicides. Compared to their predecessors, the carbamates, dithiocarbarmates and pthalimides, they were a revolutionary change in fungicides, in that they were noncontact, and extremely effective at low rates. First introduced as benomyl (other MBC fungicides include thiabendazole, and thiophanate-methyl, to name a few), once inside the plant it is metabolized to form methyl benidimidazole carbamate (MBC), which inhibits fungal mitosis via binding to tubulin, the subunit of microtubules essential to forming the mitotic spindle (Ma and Michailides, 2005).

As one of the first noncontact fungicides, it is not surprising that it was one of the first instances of resistance reported, to powdery mildew in greenhouse cucumbers (Schroeder et al. 1969). Since that time, resistance to the benzimidazole class of fungicides has been detected in many fungal species (Ma and Michelides, 2005). Resistance is correlated with point mutations in the $\beta$-tubulin gene, with different mutations resulting in altered amino acid changes at the benzimidazole-binding site. These various mutations at different codon sites also result in different levels of resistance: In $V$. inaequalis, mutations at codon 198 resulted in medium resistance, at codon 200 it resulted in very high resistance (Koenraadt et al. 1992a), and at 240 it resulted in low resistance (Quello et al. 2010). In Monilinia, only low and high resistance to benomyl and thiophanate-methyl has been observed for field isolates of M. fructicola (Ma and Michelides, 2005). Sequence analysis of the $\beta$-tubulin gene showed that a single base pair mutation at codon 6 was responsible for the low resistance level to benzimidazoles in all the LR isolates of M. fructicola examined. Curiously, different substitutions at the same codon resulted in different degrees of resistance in the cereal eyespot fungus, Tapesia yallundae (Pseudocercosporella herpotrichoides): codon changes from Glu to Ala, Gly, Lys, and Gln at position 198 had 50\% effective concentration (EC50) values to carbendazim ranging from 0.5 to more than $25 \mathrm{~m} \mathrm{~g} / \mathrm{ml}$ in some isolates (Albertini et al., 1999), one of the first instances that demonstrates that differences in genetic background may play a role in expression of specific fungicide resistance genes.

PCR-CAPS was used to determine thiophanate-methyl resistance Helminthosporium solani (Cunha and Rizzo, 2005). In V. inaequalis, a screen using this approach resulted in the identification of previously unidentified alleles conferring resistance in this fungus, and would have under-reported MBC resistance in 31\% of the isolates (Quello et al. 2009) if PCR 
alone was used for detection. Although the authors continue that a PCR-RFLP based assay may be the best option to screen for fungicide resistance from late-season scab lesions because $V$. inaequalis cannot be reliably cultured due to the application of protectant fungicides for other diseases and competing leaf microflora later in the season, it still leaves open the possibility of new alleles for resistance not being identified, and resistance being under-reported. At this point in time, most apple growers have abandoned thiophanatemethyl for the control of apple scab in the field, although it continues to be used for other diseases. However, these studies are a cautionary tale regarding the sole use of a PCR-based detection to identify fungicide resistance, particularly when no in vitro screening is performed in parallel. This is particularly important as Kawchuk et al. (2002) found that mechanisms other than point mutations in the $\beta$-tubulin gene play a role in resistance on Gibberella pulicaris; work in the human pathogen, Candida albicans, identified the role of a multidrug resistant transporter (MDR) as responsible for benomyl resistance (Ben-Yaacov et al. 1994). Later work by Sanglard et al. (1995), identified the $B E N^{R}$ gene that confers resistance to $\beta$ -tubulin as an ATP-binding cassette (ABC) transporter (Sanglard et al. 1999).

Detection of specific types of benzimidazole resistance also identifies any negative crossresistance with diethofencarb (Leroux et al. 1999). The phenylcarbamate diethofencarb was introduced in 1984, and has a similar mode of action to the MBC class of fungicides. In fact, single base pair mutations in codons 198 and 200 result in a readily detectable, negative cross-resistance to diethofencarb (Faretra and Pollastro, 1991; Yarden and Katan, 1993). Negative cross-resistance (NCR) occurs when a novel allele that confers resistance to one toxic chemical results in hyper-sensitivity to another. This mutation therefore results in efficacy to benzimidazole-resistant isolates that possess that allele, but not wild-type isolates. In B. cinerea, high levels to resistance carbendazim and thiabendazole, conferred hypersensitivity to diethofencarb, even more so than the benzimidazole sensitive type (Leroux et al. 1999). Furthermore, this negative cross-resistance involved other Nphenylcarbamates and other herbicides that target microtubule assembly (Leroux and Gredt, 1989). Negative cross-resistance was also observed between benzimidazoles and several aromatic hydrocarbon fungicides (e.g., dicloran, OPP (o-phenylphenol)); the phenomenon was first described in cereal eyespot fungus, T. yallundae, as well (Leroux and Gredt, 1989), but is more likely due to multi-drug resistance (MDR) mutations than a single structural gene.

\section{Signal transduction: Dicarboximides and phenylpyrroles}

The dicarboximides are composed of three major products: Iprodione, vinclozolin, and procymidone. The introduction of this class of fungicides coincided with the failure of the benzimidazoles in control of Botrytis in grape. As with benzimidizoles, resistance developed rapidly, due to a combination of concurrent applications of this class without rotation or tank-mixing with other products, coupled with a limited understanding of the process of fungicide resistance. This class of fungicides was primarily used for the control Botrytis, Alternaria, Sclerotinia diseases, although they are effective on other pathogens like 
Rhizoctonia spp., and Fusarium spp., as well. Not surprisingly, field resistance was first observed in B. cinerea (Pommer and Lorenz, 1982), M. fructicola (Ritchie, 1983), and Sclerotinia spp. (Detweiler et al., 1983).

The molecular mechanisms of dicarboximide resistance involve two separate signal transduction pathways: The two-component histidine kinase and mitogen-activated protein (MAP) kinase cascades. Both MAP kinase and two-component histidine kinase are involved with regulating a diversity of cellular responses including differentiation, cell division, gene expression, heat shock and osmotic response. The first molecular mechanism of dicarboximide resistance was identified in U. maydis (Orth et al. 1994), and is one of the few instances where the gene was found to be sufficient for conferring resistance to a wild-type isolate via transformation (Orth et al. 1995). The gene, termed adr1, is a 1,218 bp open reading frame with homology to serine/threonine protein kinases that was later identified as the major cAMP dependent protein kinase; However, later studies by Ramesh et al. (2001), found that the adr1-encoded enzyme was not the direct target of vinclozolin inhibition but that mutants with a defect in the regulatory subunit of cAMP-dependent protein kinase (ubc1) exhibited resistance to vinclozolin and the aromatic hydrocarbon, chloroneb. Mutants with a defect in the $u b c 1$ gene also display interesting changes in morphology, including a reduction in multiple budding in the presence of the fungicides and osmotic sensitivity, suggesting a connection between fungicide mode of action and morphogenesis and glycerol accumulation (which would also be related to osmotic, turgor regulation and osmotic shock), which may explain why this mutation has never been reported from field isolates with fungicide resistance phenotypes (Ramesh et al. 2001).

Studies by Leroux et al. (1999) in B. cinerea in French vineyards found strains resistant to multi-site fungicides, and multiple combinations of fungicide resistant phenotypes in vineyards in France: two types of benzimidazole (e.g. carbendazim, thiabendazole)-resistant strains were detected, with negative cross-resistance towards the n-phenylcarbamates (diethofencarb, diphenylamine and dicloran) found only in one type of resistant strain, as previously stated above. However, this study also found that most dicarboximide (e.g. iprodione, procymidone, vinclozolin)-resistant strains were also weakly resistant to aromatic hydrocarbon fungicides (e.g. chloroneb, dicloran, tolclofos-methyl) but remained sensitive to phenylpyrroles (e.g. fenpiclonil, fludioxonil). However, in some other dicarboximide-resistant strains, resistance was observed either as being restricted to dicarboximides or as extending weakly to phenylpyrroles. Dicarboximides, phenylpyrroles and the aromatic hydrocarbon fungicides (e.g. chloroneb (PCNB), dicloran, quintozene, tolclofos-methyl) are not chemically related, but obvious structural similarities can be observed (Fig. 3), and in laboratory studies, mutants of B. fuckeliana and several other fungi, have a positive cross-resistance between them (Leroux et al., 1992; Faretra and Pollastro, 1993).

Similar observations regarding the complexity of resistance profiles were observed in $B$. cinerea in the laboratory (Oshima et al. 2002). Dicarboximide- resistant laboratory mutants selected for high resistance to dicarboximides, aromatic hydrocarbons, and phenylpyrroles, were hypersensitive to osmotic stress, and were rarely obtained from the field (Leroux et al., 
<smiles>O=[N+]([O-])c1c(Cl)c(Cl)c(Cl)c(Cl)c1Cl</smiles><smiles>CC(C)NC(=O)N1CC(=O)N(c2cc(Cl)cc(Cl)c2)C1=O</smiles><smiles>N#Cc1c[nH]cc1-c1cccc2c1OC(F)(F)O2</smiles>

Fludioxonil

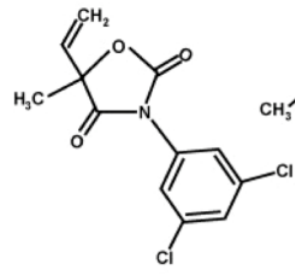

Vinclozolin

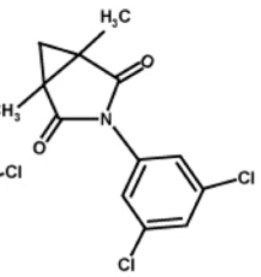

Procymidone

Figure 3. Comparison of members of the aromatic hydrocarbons (PCNB), phenylpyrrole fungicide fludioxonil and three dicarboximides, iprodione, vinclozolin and procymidone. All five structures share low molecular weight and aromatic hydrocarbon moieties that may explain why some cross resistance between these distinct classes of fungicides is observed.

1992; Faretra and Pollastro, 1993; Lyr, 1995). Instead, only moderately resistant, osmoticallystable strains were recovered from the field, and these field isolates of $B$. cinerea showed cross-resistance to aromatic hydrocarbons but not to phenylpyrroles (Oshima et al. 2002). In fact, phenylpyrrole- resistant mutants from $B$. cinerea that were first isolated and characterized in the laboratory were due to mutations at a different locus (Daf1-later identified as $\mathrm{BcOS1}$ ) locus responsible for dicarboximide resistance (Faretra and Pollastro, 1993) and were only later found in the field, and were only described as "weakly resistant"(Leroux et al. 1999). These early studies found that mutations of the DafI gene are highly variable, with at least five classes of alleles identified and associated with differing levels of resistance (sensitive (S), low resistance (LR), moderate resistance (MR) or highlyresistant (HR)) to dicarboximides and phenylpyrroles, respectively: S/S, LR/S, HR/LR, HR/MR, HR/HR (Faretra and Pollastro, 1993). Field resistance was due to a single amino acid substitution, from Ile to Ser, which occurred at codon 365 in BcOS1 gene (Oshima et al. 2002), and at two other amino acid substitutions at the same position, 365 Ile to Asn or Arg, in field-resistant isolates. Work done by Oshima et al. (2006) used PCR-CAPS, exploiting a Taq1 restriction site that results in the mutant allele that confers resistance. Approximately 41 percent of the isolates had the type I mutation that could be detected by PCR-CAPS. However, other types of dicarboximide resistance were detected and sequence analysis of these mutants classified them into type II isolates that have three amino acid substitutions 
within BcOS1p (V368F, Q369H, and T447S) or type III isolates that have two amino acid substitutions within BcOS1p (Q369P and N373S) (Oshima et al. 2006).

Many fungi accumulate glycerol to increase osmotic pressure to contend with osmotic stress, or for pathogenicity. Studies done by Fujimura et al., (2000) in Neurospora crassa with osmotic-sensitive (os) mutants with os-1, os-2, os-4 and os-5 mutations (similar to the previously described resistances in $B$. cinerea) showed cross-resistance to dicarboximides (iprodione and vinclozolin), but also the aromatic hydrocarbons (PCNB). All of the os mutants except for some os- 1 mutant alleles were resistant to the phenylpyrrole fungicide, fludioxonil (Ochiai et al. 2002). Previous work by Grindle (1982) found other osmotic sensitive mutants (cut) that were not resistant to these fungicides, suggesting that osmotic sensitivity alone was not the mechanism. However, the original report by Grindle (1982) on dicarboximide resistance in $N$. crassa shows that multiple alleles that segregate independently were involved with this os-1 resistance, suggesting that other genes may still be involved in resistance (See section on MDR for further information). Work by Zhang et al. (2002), identified a mitogen activated protein (MAP) kinase (HOG1) that was resistant to phenylpyrrole, and were caused by a frame shift from tryptophan to a stop codon or nonsense point mutations, allowing for a screenable genotype. However, field resistance of phenylpyrrole has not been reported to date, and the complex phenotype involved in this type of resistance makes it biologically interesting, but hardly defining in the diagnosis of fungicide resistance.

\subsection{Sterol biosynthesis inhibitors}

This group of fungicides exploits one of, if not the most important mode of action for both antifungals in medicine and fungicides in agriculture. The sterol biosynthesis inhibitor (SBI) fungicides inhibit a precursor of ergosterol that is essential for the development of the fungal membrane (Brent, 1995). These fungicides can be classified based upon their target sites in sterol biosynthesis, with inhibitors of squalene epoxidase (e.g. naftifine, terbinafine, tolnaftate) primarily used for mammalian mycoses. The remaining classes are used for agricultural purposes. 'Amines' or 'morpholines' (e.g. fenpropidine, piperalin, spiroxamine, tridemorph) act as inhibitors of sterol $\Delta 14$-reductase or $\Delta 8-\Delta 7$-isomerase, and target the products from the Erg24 and Erg2 genes; hydroxyanilides, represented by fenhexamid, act on the 3-keto reductase, C4- demethylation encoded by Erg27 and is specifically used for the control of Botrytis; inhibitors of sterol 14-alpha-demethylase (e.g. bitertanol, triazoles, imidazoles, in addition to imazalil, prochloraz, pyrifenox, triadimenol) are referred to as demethylase inhibitors (DMIs) and primarily target Erg 11/CYP51(FRAC 2012), and are effective against a wide variety of phytopathogens.

DMIs were introduced for plant disease management in the 1970s, with resistance and reduced efficacy reported soon after (Brent, 1995). Due to both agricultural and medical importance, the molecular mechanisms of SBI resistance have been highly studied and include (i) mutations in 14-alpha-demethylase (CYP51) structural gene (Delye et al. 1997; 1998; Canas-Gutierrez et al. 2009, and others) and ERG27 gene (Albertini and Leroux, 2004; 
Fraaije et al. 2007); (ii) overexpression of the CYP51 gene, leading to increased production of the target enzyme (Cools et al. 2012; Luo et al. 2008; Ma et al. 2006; Schnabel and Jones, 2001; Hamamoto et al. 2000), and (iii) overexpression of the ATP-binding cassette (ABC) transporters (Zwiers et al. 2002; Hamamoto et al. 2000; Nakaune et al. 1998) which will be addressed later in the chapter. Several studies, at least in the laboratory, have demonstrated that multiple mechanisms contribute to the variation in azole susceptibility (Stergiopoulis et al. 2003; Zwiers et al. 2002), and genetic analysis of progeny from a cross between $M$. graminicola isolates with differing sensitivities to DMI fungicides revealed a continuous distribution of resistance, leading the researchers to conclude on the polygenic nature of inheritance (Stergiopoulis et al. 2003), leaving open the possibility that other mechanisms may also be at work.

Mutations in the 14-alpha-demethylase (ERG11/CYP51) structural gene that lead to a decreased affinity of the target protein to DMI fungicides have been found in powdery mildews (Delye et al. 1998; Delye et al. 1997); two Mycosphaerella pathogens-M. graminicola (Leroux et al. 2007; Cools et al. 2006) and the black Sigatoka fungus, M. fijiensis, (GutierrezCanas et al. 2009); and the cereal leaf spot pathogens--Tapesia spp. (Albertini et al. 2003), although work by Wood et al. (2001) did not find a correlation between resistance and the presence of known mutations in the structural gene. In M. graminola, reduced sensitivity to DMIs could be correlated with an alteration in the CYP51 structural gene at codons 459-461 (Cools et al. 2005; Leroux et al. 2007). In the barley powdery mildew, Blumeria graminis, amino acid substitutions in CYP51 at Y136F and K147Q, were detected and a very high level of resistance was associated with the allele containing K147Q mutation. Sequence analysis of the CYP51 gene from the progeny of a cross between DMI-sensitive and resistant isolates demonstrated co-segregation between the mutant alleles and resistance. Consistent with other studies, the authors found that genetic analysis of resistance to the triadimenol indicates that mutation of the CYP51 gene is not the only mechanism of resistance operating in B. graminis: Two moderately resistant isolates had no mutations in the CYP51 gene, and had identical sequences to that of the sensitive isolate, suggesting that resistance in at least these two isolates must be due to a mutation in an entirely different gene (Wyand and Brown 2005). The identification of isolates such as these should serve as adequate warning that molecular detection of mutations in the structural gene may result in an underreporting of actual incidence of resistance in the field. Finally, mutations in the structural gene of ERG27 in B. cinerea were detected and correlated with mutations (F412I and R496H) that would lead to a decreased affinity of fungicide to the target protein, but it was regarded as low resistance or moderate resistance (Albertini and Leroux, 2004; Leroux et al. 2007).

A second mechanism of DMI resistance involves overexpression of the CYP51 gene. Overexpression of CYP51 has been associated with DMI resistance in $P$. digitatum (Hamamoto et al. 2000), V. inaequalis (Schnabel and Jones, 2001), M. fructicola (Luo et al. 2008), B. jaapii (Ma et al. 2006), C. beticola (Bolton et al. 2012) and M. graminicola (Cools et al. 2012). In all but $C$. beticola, overexpression of CYP51 has been associated with insertions in the upstream promoter: A tandemly repeated $126 \mathrm{bp}$ fragment was found in the promoter of $P$. digitatum; Ma et al. (2006) identified a variably-sized retrotransposon-like element in $B$. 
jaapi; Schnabel and Jones (2001) reported on a 533-bp fragment found in some (but not all) DMI-resistant isolates of $V$. inaequalis; and Luo et al. (2008) found a 65 bp 'Mona' element in the promoter of CYP51 in M. fructicola that was strongly linked to the DMI resistance phenotype. However, subsequent work by Villani and Cox (2011), found that the 'Mona' element was present in a range of sensitivities, and not always present in resistant isolates, suggesting it is just one of many possible mechanisms of resistance. Overexpression of ERG27 has not yet been identified as having a role in resistance to the hydroxyanilide class (FRAC 17) of fungicides.

A final mechanism of DMI resistance relies upon "drug" transporters, trans-membrane proteins located in the plasma membranes that utilize ATP to translocate compounds, including toxins, out of the cell, preventing the accumulation of these products to toxic levels, as has been shown for B. cinerea (Leroux and Walker 2011; Leroux et al. 2002), M. graminicola (Cools et al. 2007) Penicillium digitatum (Nakaune et al. 1998), and possibly $V$. inaequalis (Koller and Wilcox, 2001). This will be discussed in a later section. Some moderate resistance to DMI fungicides in B. cinerea (termed Ani R2 and Ani R3 by Leroux et al., 1999) was previously described (Stehmann and DeWaard, 1995; Del Sorbo et al. 1997). Later studies found isolates with this similar phenotype demonstrated pronounced increases in expression level of the ABC transporter genes (Kretschmer et al. 2009) and not the structural genes themselves, creating greater complexity and less certainty in molecular detection of fungicide resistance. As a result, DMI resistance in numerous species has been identified, but only 10 species have had the molecular mechanism of resistance studied in depth.

Although fungicide resistance baselines and thresholds have been previously established in many agricultural systems, the primary stumbling block to the rapid identification of DMI fungicide resistance for most fungi is the nature of its quantitative resistance (Koller et al. 1991; Schnabel and Jones, 2001; Ishii, 2009). Unlike qualitative resistance that results from a single gene mutation (e.g., TUB1R conferring resistance to benzimidazoles), DMI resistance is much more complex. Due to the diversity of mechanisms of DMI resistance in different pathogens (and even the variation in response by pathogens to different DMIs), it is unlikely that any one approach, with the exception of phenotypic analysis, will provide the screening necessary to detect fungicide resistance in a diversity of pathosystems, although the possibility exists that the monogenic DMI resistance observed in powdery mildew pathogens may be amenable to this approach. In V. inaequalis, examples of DMI resistance to date are associated with an insertion in the promoter of the CYP51 target gene that has been correlated with overexpression of CYP51. The authors of this work (Schnabel and Jones, 2001) noted that the correlation was strong, but not absolute. Subsequent work to utilize this knowledge to develop PCR based screening of resistant isolates can detect the insertion, but not predict the degree of resistance that results (Villani, Cox and Beckerman, in preparation and Fig 4.), preventing the rapid detection of resistance in the field. Ultimately, in vitro screening of radial growth in the presence of fungicide (a 4-week process after a single-spore isolate in pure culture is established) is needed to determine the degree of resistance in the isolate, and at least in $V$. inaequalis, it does not seem to be currently possible to rapidly detect fungicide resistance in the field, and certainly not to a degree that thresholds could be 
identified to warn when a fungicide failure will occur. This situation is quite different than the detection of fungicides that impact respiration.

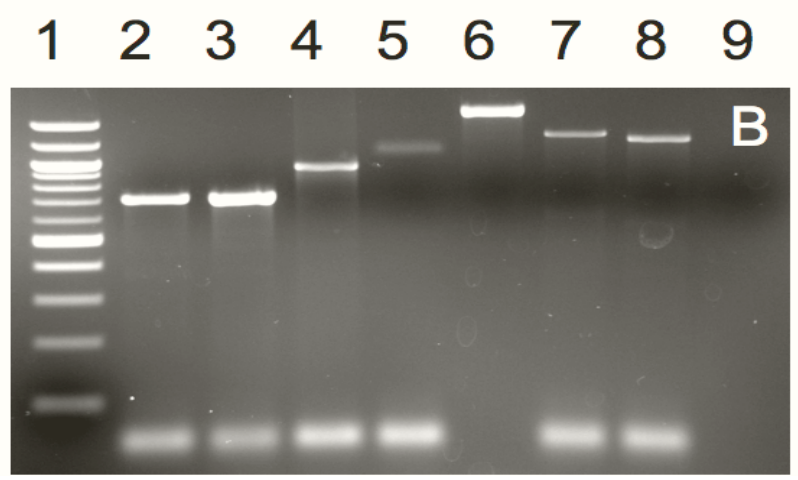

Figure 4. Amplicon size is not related to overexpression of CYP51 in V. inaequalis. Primers flanking the promoter region of CYP51 were used to examine the relationship between the $533 \mathrm{bp}$ insertion, size of promoter insertion and resistance to myclobutanil. Many of the highly resistant isolates did not yield an amplicon, and those that did did not have the expected 533 bp insertion. From Villani, Cox, and Beckerman, unpublished.

\subsection{The respiration inhibitors}

Respiration is an obvious target for fungicides. The oldest synthetic fungicides still used today include dithiocarbamates (e.g., mancozeb, thiram, ziram) or pthalimide derivatives (e.g., captan), and prevent plant disease by the inhibition of spore germination, and subsequent germ tube elongation. To date, there have been no credible reports of resistance to these older fungicides. Furthermore, older synthetic multi-site fungicides are effective against a wide range of plant-pathogenic fungi, and Chromista. These multisite inhibitors are thio-reactant with those enzymes involved in respiration (Lyr, 1977); Other inhibitors of respiration work at complex II at the succinate dehydrogenase gene, complex III, the cytochrome bc1 (ubiquinol oxidase) at Qo site, or cytochrome bc1 (ubiquinol oxidase) at Qo site; or complex $\mathrm{V}$, where fungicides like fluazinam actually work by uncoupling electron transport and ADP phosphorylation of oxidative phosphorylation (FRAC, 2009). As such, this target is essential to aerobic eukaryotes, and present targets for disruption. The most recently developed group of respiration inhibitors targets mitochondrial complex III (the cytochrome bc1 complex), and targets the outer quinol-oxidizing pocket (Qo site), and complex II at the succinate dehydrogenase gene, which are the areas of most recent and active interest due to their recent release, the nature of fungicide resistance, and potential ease of detection.

\subsection{QoI-The quinone outside inhibitors}

Fungicides that inhibit the cytochrome bc1 enzyme complex (complex III) at the Qo site (Qo inhibitors, QoIs) were first introduced to the market in 1996. QoI resistance has now been 
reported in more than 20 pathogens, including the Chromista pathogens, downy mildew of grape and cucurbit, and the fungi that cause apple scab, wheat powdery mildew and Septoria leaf blotch, to name but a few. Resistance has been reported in all major continents: Asia, Australia, Europe, North America, and South America (FRAC 2006; Wilson and Wicks, 2011). The majority of the reports associate the point mutation that results in a change from glutamate to alanine at codon 143 (G143A), followed by the resistance that results from a transition from phenylalanine to leucine at position 129 (F129L) (Pasche et al. 2005; Sierotzki et al. 2007); the least commonly observed mutation involves a change from glycine to arginine at position 137 (G137R) (Sierotzki et al. 2007), and of course, unknown causes (Lesniak et al. 2011). These easily identified mutations allow for the rapid detection for the potential of QoI-resistance in a variety of fungi and Chromista. Furthermore, the degree of resistance is much greater in the G143A allele (referred to as high resistance), and has consistently resulted in a significant reduction in disease control, as compared to resistance associated by F129L and G137R which results in more moderate or partial resistance, and some degree of control at highest rates of fungicide.

A more recent study by Lesniak et al. (2011), found ninety-eight percent of QoIresistant/shifted isolates screened in Michigan were associated with G143A, consistent with other phytopathogenic fungi resistant to this class of fungicides (Ishii et al., 2009; Ishii et al. 2007). Sequencing the entire $C Y T b$ gene of resistant isolates that did not test positive for the G143A transition did not reveal other mutations in the structural gene, and suggests other mechanisms of resistance (Lesniak et al. 2011). Regardless of mutation present, functional analysis of the $C Y T b$ gene is confounded by the complexity of fungal mitochondrial genetics. A fungal cell may contain $>250$ mitochondria and an equal copy number of mitochondrial DNA (mtDNA). A single point mutation in a single copy of a mitochondrial gene could be detected, but would not be sufficient to confer resistance, unless multiple copies of the allele were present. However, over time, and under increasing selection pressure, the allele would become fixed, and the mitochondria population within the cell would shift from sensitive to increasing numbers bearing the resistant allele, shifting resistance and becoming homeoplasmic over time. Thus, early detection of this shift could preserve long-term fungicide efficacy by short-term use of alternative fungicides until the allele shifts back to the previous susceptible homeoplasmy. Early detection with quantitative PCR (qPCR) could theoretically enable the assessment of either gene expression or copy number that is required for QoI resistance to develop the field. However, to date, this work has not been attempted with any field populations. Preliminary data suggests that the populations in New York, Michigan and Indiana are not yet fixed (heteroplasmy). Laboratory analysis of QoI resistant mutants found that serial passage of trifloxystrobin-resistant isolates in vitro has resulted in a loss of resistance In $V$. inaequalis, after only two rounds of propagation allowed a significant majority of mitochondria containing the wild-type cytochrome $b$ sequence to re-appear; This was not observed when the fungus was under continued selection (Zheng et al. 2000) . The conversion of heteroplasmic isolates back to wild type in the absence of QoI fungicides would imply that a G143A mutation is associated with a fitness penalty, although Chapman et al. (2011) found no evidence of this. Early detection of the resistance allele, and prophylactic switching to non-QoI fungicides may return the 
population of a sensitive level in a few years, and with proper monitoring, allow the use of QoI fungicides for scab control again. Similar findings on M. graminicola also showed conversion of mutated $C y t B$ gene back to wild-type in M. graminicola (Fraaije et al. 2002).

With QoI resistance, allele specific PCR (Lesniak et al. 2011 and many others) and restriction enzyme digest of the amplicon (Leroux et al. 2010 and many others) are both used to detect the presence of the allele. Work by Fontaine et al. (2009), found that the QoI-resistant allele could not be detected after Fnu4HI digestion for R : S ratios equal to or below 1:9 (w:w). When compared to the allele specific (AS-PCR) PCR, the mutant allele was amplified at the lowest ratio tested, much more sensitive than the PCR-CAPS technique (Fontaine et al. 2009). However, work by Chapman et al. (2011), suggests an over prediction of resistance, if the mutation is used as a sole criterion for identification of resistance. Similar finding occurred in work done by Lesemann et al. (2007), on apple powdery mildew, with PCR of cleaved amplified polymorphic sequences (CAPS) analyses suggest that the proportion of mitochondria carrying the G143A exchange determines the degree of strobilurin resistance. Lesemann et al. (2007) also found a high variability in the cytB gene of P.leucotricha and discusses the role that mitochondrial heteroplasmy may play in conferring a selective advantage under changing conditions, as does Avila-Adame et al. (2003). Many papers on QoI-resistance in phytopathogens fail to discuss mitochondrial heteroplasmy (Patel et al. 2011). This is important as for P. leucotricha (Lesemann et al. 2007) and V. inaequalis in the laboratory (Zheng et al.2000) and in the field (Lesniak et al. 2011), clearly demonstrated that all isolates of the apple powdery mildew and scab pathogens tested were heteroplasmic for the G143A mutation. Lastly, a study by Miguez et al. (2003), examined the role of alternative oxidase in reducing the sensitivity of M. graminicola to the QoI azoxystrobin. Although the level of resistance was lower than the more commonly identified, G143A, sufficient resistance was incurred despite the absence of this mutation, suggesting yet another mechanisms of resistance.

\subsection{SDHI}

Succinate dehydrogenase inhibitor (SDHI) fungicides include "first generation" SDHIs, like flutolanil, carboxin, followed by later (and improved) "second generation" compounds, including boscalid, and even "third generation" products like penthiopyrad, and fluopyram. This class of compounds targets and binds to the ubiquinone-binding site (Q-site) of the mitochondrial complex II, specifically the succinate dehydrogenase (SDH) complex in the respiratory chain also referred to as complex II or succinate:ubiquinone oxidoreductase (SQR), inhibiting fungal respiration by blocking electron transport [Kuhn, 1984; reviewed by Avenot and Michailides (2010), including a recent list of resistant organisms and corresponding mutations]. There is no evidence of cross-resistance with other similarly acting chemical classes such as QoI fungicides (which also affect energy production and electron transport) due to their unique mode of action and target site. The primary target of the SDHI fungicides is the SDH complex that consists of four subunits: a flavoprotein (Fp) subunit $(\mathrm{SdhA})$, an iron-sulfur protein (Ip) subunit (SdhB), and two membrane-anchored protein subunits (SdhC and SdhD). Mutations conferring resistance have been found in the SDHB (Avenot et al 2008) and SDHC (Ito et al. 2004) and SDHD subunits (Avenot et al. 2009). 
The first widely used SDHI fungicide, carboxin, was used in the late 1960s, and its applications were limited due to its primary activity against basidiomycete pathogens, namely rusts, Rhizoctonia spp., and corn smut (Ustilago maydis), and limited activity against other pathogens (Sisler 1988). In contrast to old SDHIs, newer active ingredients of SDHIs comprise compounds such as boscalid, penthiopyrad or fluopyram, and are characterized by a broad spectrum of fungal activity on various crops (Stammler et al., 2007; Stammler et al., 2006) particularly Botrytis and Alternaria species. Carboxin is less efficient than boscalid in controlling the wild-type sensitive isolates (Avenot et al. 2008). Unlike carboxin, boscalid prevented $B$. cinerea spore germination completely at high concentrations, and inhibited germ-tube elongation at low concentrations. This phenomenon was particularly noticeable if biological tests were conducted in media containing succinate rather than glucose as the carbon source (Lyr, 1977). This is an important point when performing in vitro screens of fungicide resistance phenotypes.

Field and laboratory mutants resistant to carboxin and boscalid have been reported in a variety of fungi and cropping systems (For a recent review see Avenot and Michailides 2010). Carboxin and other SDHI fungicide resistances are described as monogenic, and have been identified in both field and laboratory. Sequence analysis of the gene encoding the target protein, the succinate dehydrogenase enzyme (SDHB), revealed that single or double point mutations in the highly conserved regions of gene were associated with resistance. Different levels of resistance are associated with mutations in different alleles: In B. cinerea, mutations resulted in P225L or P225F transitions that confer high resistance, and in a histidine to tyrosine replacement at position 272 (H272Y) or Arg (H272R) (Avenot et al. 2008), although Angelini et al. (2010) found these two mutations resulted in a lower level of resistance. In A. alternata, sequence analysis of the SDHB gene from sensitive and resistant isolates identified a $\mathrm{H} 277 \mathrm{Y}$ and $\mathrm{H} 277 \mathrm{R}$ transitions, as well. (Avenot et al. 2008). It is important to note that in some boscalid-resistant strains of A. alternata, there were no identifiable mutations in the AaSdhB gene as compared to the wild type, suggesting that mutation(s) in other loci are involved in the boscalid resistance phenotype. This is not surprising since the boscalid mode of action involves at least two other genes of the Sdh complex (SdhC or SdhD) (Avenot et al. 2009).

Despite the elucidation of the molecular mechanisms of resistance, mycelial growth assay in liquid medium in microtiter plates were developed to monitor fungicide resistance, in $A$. alternata (Avenot and Michailides 2007) and a variety of other fungi, eventually resulting in the development of rapid in vitro monitoring procedures with a single discriminatory dose of boscalid (Avenot and Michailides, 2010), despite the eventual elucidation of many of the molecular mechanisms of resistance.

\subsection{MDR-efflux pumps and resistance}

All living organisms, eukaryote and prokaryotic, are exposed to both food and toxins in their natural environments. To quote Pao (1998), "Transport systems allow the uptake of essential nutrients and ions, excretion of end products of metabolism and deleterious 
substances, and communication between cells and the environment." Some of these deleterious substances may be antibiotics produced by bacteria and actinomycetes, antifungals [e.g., strobilurin A produced by Strobiluris tenecellus, killer yeast strains, plant defense compounds (phytoalexins, alkaloids, small molecular weight peptides)], and heavy metals. There are two protein families that are key players in this type of transport process: The ATP-binding cassette (ABC) and the major facilitator superfamily (MFS) of transporters. $\mathrm{ABC}$ transporters are able to bind and hydrolyze nucleotide triphosphates (mainly ATP) due to a conserved cytosolic, nucleotide-binding fold (NBF or ATP-binding domain) and use this energy to transport solutes across cell membranes (Higgins, 1992). MFS transporters work as a "secondary" active transport system that does not require ATP for functionality, and are capable only of transporting small solutes in response to chemiosmotic ion gradients (Pao 1998). These two families of transporter proteins can mediate a quantitative multidrug resistance (MDR) to multiple classes of fungicides, however, the resistance levels conferred against individual fungicides are greatly reduced as compared to fungicide resistance conferred by target site mutations (de Waard et al. 2006; Mernke et al. 2011).

In the human pathogen $C$. albicans, the role of MDR transporters and resistance is fairly straightforward: The $\mathrm{ABC}$ transporter, $\mathrm{CDR} 1$, plays a major role in resistance (in a majority of isolates) to fluconazole and miconazole due to upregulation of the gene (Sanglard et al., 1995) resulting in increased efflux of the antifungal and its decreased accumulation in the cell, thereby reducing inhibition of the ERG11/CYP51 gene in most isolates resistant to fluconazole. In addition to its role in resistance to azoles, CDR1 also confers resistance to other sterol biosynthesis inhibitors, including allylamines and morpholines, in addition to several other drugs. A separate transporter, referred to BENR, was highly overexpressed and conferred resistance to azoles and benomyl (Sanglard et al., 1999; Sanglard et al., 1995).

Detection of this type of fungicide resistance has proven to be more difficult, or at least less published, in plant pathogens. Numerous reports exist about multiple fungicide resistances in plant pathogens (Leroux et al. 1997, Nakaune et al. 1998; Leroux et al. 1999; Kretchmer et al. 2011; Chapman et al. 2011). It is important to stress that not all of these multiple fungicide resistances are due to MDR, but in fact, are due to other mechanisms (see the section on Dicarboximides for elucidation of one such mechanism) including segregation of separate, multiple resistances (Chapman et al. 2011). One of the first studies (Leroux et al. 1999) that screened multiple fungicide resistances in B. cinerea found resistance to anilopyrimidines (AP, e.g. cyprodinil, mepanipyrim, pyrimethanil) and identified two distinct resistance phenotypes: The most AP-resistant isolates were resistant to only anilinopyrimidines, suggesting action on the hitherto unidentified, single target gene (Hilber and Hilber-Bodmer 1998) and a second phenotype that included resistance to distinctly different classes of fungicides including dicarboximides, phenylpyrroles, sterol biosynthesis inhibitors (e.g. tolfanate, prochloraz, tebuconazole) and the hydroxyanilide derivative, fenhexamid, consistent with an MDR phenotype.

The role of MDR in fungicide resistance was further strengthened by work by Kretschmer et al. (2011) who found that fungicide resistant field isolates from France and Germany 
exhibited three distinct MDR phenotypes of increased fungicide efflux activity and overexpression of efflux transporter genes. In this study, MDR1 strains were found to possess mutations in the transcription factor, Mrr1, that controls the $\mathrm{ABC}$ transporter gene AtrB; the MDR2 strains possessed insertions of a retrotransposon-derived sequence in the promoter region of the major facilitator superfamily (MFS) transporter gene mfsM2 (more thoroughly described by Mernke et al. 2011), and the MDR3 strains which showed the highest levels and broadest spectrum of resistance against most fungicides tested, and was identified as recombinants carrying both MDR1-specific mutations in mrr1 and MDR2specific mutations in mfsM2 (Kretschmer et al. 2011). All MDR strains showed strong constitutive overexpression of either one (MDR1, MDR2) or two (MDR3) drug efflux transporter genes. MDR1 and MDR3-described isolates had an increased efflux for fludioxonil whereas MDR2 strains did not, while bitertanol efflux was observed for all MDR phenotypes, although MDR1 possessed a less resistant phenotype. Prior to this, Hayashi et al. (2001) found in laboratory isolates, overexpression of the ABC Transporter Gene BcatrD involved in resistance to two azoles, in addition to the dicarboximide fungicide iprodione, the benzimidazole fungicide carbendazim, and the antibiotic cycloheximide.

In M. graminicola, laboratory isolates were selected with decreased azole susceptibilities and cross-resistance to chemically unrelated of low molecular weight compounds (Zwiers et al. 2002). Later studies found field isolates showed differences in both basal and induced levels of $\mathrm{ABC}$ transporter gene transcript, although no correlation between increased expression and azole sensitivity was evident (Stergiopoulos et al., 2003); Cools et al. (2007) were unable to establish a direct relationship between over-expression of the $\mathrm{ABC}$ transporters and decreased azole sensitivity, and later studies, using cDNA microarrays to profile the transcriptional response of $M$. graminicola to epoxiconazole, and compared the expression profiles of an azole-sensitive and less sensitive M. gramincola isolates did not find a relationship. They found upregulation of ten genes that provided different constitutive expression profiles between the two strains, including drug transporters, a cell surface glycoprotein, stress response protein rds1, and an unknown gene encoding a homologue of the antibiotic response protein in addition to differential expression between components of the sterol biosynthesis pathway between sensitive and less sensitive isolates, and components of the mitochondrial respiratory chain. (Cools et al. 2007). Thus, at least in $M$. graminicola, studies have not demonstrated a relationship between expression (or overexpression) of $\mathrm{ABC}$ transporter genes directly (Stergiopoulos et al. 2003) or by microarray (Cools et al. 2007), despite its demonstrated role in field resistance in B. cinerea.

Although the role of MDR genes in fungicide resistance is clear in some pathogens, rapid detection of fungicide resistance due to MDR is not. Some of these difficulties reside in the unclear and multiple mechanisms of DMI and other fungicide resistances discussed above, others in the role and regulation of MDR. To date, most differences identified in fungicide resistance where MDR is implicated have been found to be due to overexpression of $A B C$ transporter genes. Most important to stress is the lack of correlation between expression level specific $A B C$ transporter gene with fungicide resistance, suggesting that multiple transporters 
may be involved (at least in DMI resistance) or that other mechanisms in addition to upstream transcription factors, have not yet been identified (Cools et al. 2007; Leroux et al. 2011).

\section{Conclusions}

Fungicide resistance can be conferred by a variety of mechanisms, and plant pathologists need to recognize that multiple genes may be necessary for this resistance, and that single genes, although easily scored or detected by molecular means, may not be sufficient for determination of resistance. Central to these studies is the recognition of the strengths and the limitations of molecular detection, and the importance of phenotypic versus genotypic resistance. This requires that we recognize that the phenotype of fungicide resistance consists (in many instances) of "major" genes, "minor" genes, the interactions between these genes (epistasis) and the interactions between genes and the environment, and that many of the known mechanisms conferring quantitative fungicide resistance utilize alternative metabolic pathways, exclusion or efflux of fungicides, and hitherto unknown mechanisms (Brent and Holleman 1998; Leroux et al. 1999; Lesniak et al. 2011).

The detection of single gene targets is only the beginning, and understanding the mechanism of resistance does not provide a blueprint as to how to manage the crop in the absence of the fungicide lost. Previous studies labored under an assumption that "a timely detection of resistance levels in populations of phytopathogenic fungi in a field would help growers make proper decisions on resistance management programs to control plant diseases" (Ma and Micheilides 2005). It certainly doesn't hurt, but few instances are available where this knowledge has been translated for use to growers and resulted in inseason changes of management beyond cessation of use of the fungicide in question. To date, most resistance management consists of abandoning the fungicide that has failed, to use others (Chapman et al. (2011); Lesniak et al. (2011), Avenot et al., others); Chapman et al. (2011) is one of the few instances where fungicide resistance detection was used many years later to confirm that a fungicide could be used with some degree of successful certainty. This was determined by mycelial growth assay as no molecular detection methods currently exist to screen for dodine resistance.

Fungicide sensitivity testing using mycelial growth or germination inhibition (in petri dishes or microtitre plates) lacks the excitement and appeal of the many different molecular approaches to detect fungicide resistance. It is certainly not as fast as any molecular test, although microtiter-based assays combined with Alamar blue (AB), or resazurin provide quantifiable and early detection within days, for fast growing pathogens like Monilinia (Cox et al. 2009) or Verticillium (Rampersad 2011). AB is an oxidation-reduction indicator dye used to detect microbial respiration. In the presence of actively growing cells, the resazurin indicator is changed from an oxidized, nonfluorescent blue form to a reduced, fluorescent pink form. Inhibition of growth maintains an oxidized environment, leaving the indicator blue. Results can be easily discerned with the naked eye due to the colorimetric nature of the test, or more rapid and sensitive measurements can be taken with spectroscopy equipment. In these studies, the $\mathrm{AB}$ assay provided a rapid and reproducible method of testing 
fungicide efficacy and provide an option of deriving quantitative data in the form of degree of resistance versus the qualitative data associated with molecular detection. Use of $A B$ in fungicide resistance requires aseptic techniques that are essential for any microbial assay (Cox et al. 2009). This prerequisite proved to be insurmountable for use of this technique for fungicide resistance screening in $V$. inaequalis, and possibly other fungi. Finally, the calculated the cost of 96 reactions, excluding labor and plate reader, was found to be under $\$ 4$ per isolate for $\mathrm{AB}$ assays and over $\$ 15$ per isolate for mycelial growth assays (Cox et al. 2009) making this affordable for multiple labs and diagnostic clinics to screen for fungicide resistance as a service. Despite the lack of intellectual appeal, there are other significant advantages of fungicide resistance phenotype screening, chief amongst which is the low cost, accuracy and reliability of the screening for the fungicide resistant phenotype over the genotype, because, unless all known genes and alleles are screened are known and screened, the risk of under-reporting actual resistances exists (Quello et al. 2010), and is rarely discussed.

This is not to say that molecular detection of fungicide resistance is without merit. One of, if not the most critical challenges facing applied plant pathologists is the need for the early detection of fungicide resistance in a population. Molecular methods can be used to powerfully detect and monitor the emergence of resistance in those instances where detection is possible, to a degree that phenotypic assays cannot achieve. Unfortunately, there are few studies where this has been done, and most research ends with a proof of concept, and not the implementation of the developed technique to better manage fungicide resistance. Currently, there are few studies monitoring sensitivity and early detection through the use of sentinel plants coupled with molecular detection in those instances where the mechanism can be detected, which could provide powerful information in an early warning system to anticipate the emergence of fungicide resistance in a population and prevent its occurrence. One problem with this approach is that most models for the detection of fungicide resistance emergence should assume an initial resistance mutation frequency from anywhere from as high as $10^{-4}$ (Zwiers et al. 2002) to as low as $10^{-8}$ (Zheng et al. 2000) based upon laboratory studies.

The developing paradigm that has emerged has been the generation of mutants in the laboratory, followed by their isolation from the field in some instances (but not all), followed by phenotypic screen, and identification of mechanism (Albertini et al. 1999 to Zwiers 2002, and others.) Genotypic screens have been developed, but are rarely evaluated for efficacy and accuracy over time, let alone predictive ability or utility. Furthermore, these developments have still not helped the farmer, nor provided him or her with the information necessary to make the appropriate in-season management decision. The question that remains is if we should be willing to shift the paradigm and use the best technique to adequately address the problem of fungicide failure in the field. As we enter a post-genome period, the technology is available for the detection of even single nucleotide polymorphisms. Whether it is available to rapidly detect fungicide resistance in plant pathogens in a way that is useful for growers remains to be seen. 


\section{Author details}

Janna L. Beckerman

Department of Botany and Plant Pathology, Purdue University, West Lafayette, USA

\section{Acknowledgement}

I would like to thank Drs. Rick Latin and Kiersten Wise for our numerous and ongoing discussions on fungicide resistance, and for their review of this manuscript.

\section{References}

Albertini, C., Gredt, M., and Leroux, P., 1999. Mutations of the b-tubulin gene associated with different phenotypes of benzimidazole resistance in the cereal eyespot fungi Tapesia yallundae and Tapesia acutormis. Pestic. Biochem. Physiol. 64, 17-23.

Albertini, C., M. Gredt, and Leroux, P.. 2003. Polymorphism of 14 alpha-demethylase gene (CYP51) in the cereal eyespot fungi Tapesia acuformis and Tapesia yallundae. Eur. J. Plant Pathol. 109:117-128.

Albertini, C., and Leroux, P. 2004. A Botrytis cinerea putative 3-keto reductase gene (ERG27) that is homologous to the mammalian 17 beta-hydroxysteroid dehydrogenase type 7 gene (17 beta-HSD7). Eur. J. Plant Pathol. 110:723-733.

Avenot, H. F., and T. J. Michailides. 2010. Progress in understanding molecular mechanisms and evolution of resistance to succinate dehydrogenase inhibiting (SDHI) fungicides in phytopathogenic fungi. Crop Prot. 29:643-651.

Avenot HF, Sellam, A., and Michailides, T.J. 2009. Characterization of mutations in the membrane-anchored subunits AaSDHC and AaSDHD of succinate dehydrogenase from Alternaria alternata isolates conferring field resistance to the fungicide boscalid. Plant Pathol. 58:1134-1143.

Avenot H.F., A. Sellam, G. Karaoglanidis, and Michailides, T.J. 2008. Characterization of mutations in the iron-sulphur subunit of succinate dehydrogenase correlating with boscalid resistance in Alternaria alternata from California pistachio. Phytopathology, 98: 736-742.

Avila-Adame, C., Olaya, G., and Köller, W. 2003. Characterization of Colletotrichum graminicola isolates resistant to strobilurin-related QoI fungicides. Plant Dis. 87:14261432.

Banno, S., Fukumori, F., Ichiishi, A., Okada, K., Uekusa, H., Kimura, M., and Fujimura, M. 2008. Genotyping of benzimidazole-resistant and dicarboximide- resistant mutations in Botrytis cinerea using real-time polymerase chain reaction assays. Phytopathology 98:397-404.

Ben-Yaacov R., Knoller S., Caldwell G.A., Becker J.M., Koltin, Y. 1994. Candida albicans gene encoding resistance to benomyl and methotrexate is a multidrug resistance gene. Antimicrobial Agents and Chemotherapy. 38:648-652.

Bolton, M. D., Birla, K., Rivera-Varas, V., Rudolph, K. D., and Secor, G. A. 2012. Characterization of CbCyp51 from field isolates of Cercospora beticola. Phytopathology 102:298-305. 
Brent, K. J. 1995. Fungicide resistance in crop pathogens: How can it be managed? Global Crop Protection Federation, Brussels, Belgium. Available on-line at: http://www.frac.info/frac/publication/anhang/FRAC_Mono1_2007_100dpi.pdf. Last accessed 9/4/2012.

Brent, K.J., D.W. Holleman, 1998: Fungicide resistance: the assessment of risk. FRAC Monograph II. Global Crop Protection Federation, Brussels, Belgium.

Cañas-Gutiérrez, G.P., Angarita-Velásquez, M.J., Restrepo-Flórez, J.M., Rodríguez, P., Moreno, C.X. and Arango, R. 2009. Analysis of the CYP51 gene and encoded protein in propiconazole-resistant isolates of Mycosphaerella fijiensis. Pest Manag Sci 65: 892-899.

Chapman, K. S., Sundin, G. W., and Beckerman, J. L. 2011. Identification of resistance to multiple fungicides in field populations of Venturia inaequalis. Plant Dis. 95:921-926.

Cools, H.J., Bayon, C., Atkins, S., Lucas, J.A. and Fraaije, B.A., 2012. Over-expression of the sterol 14 $\alpha$-demethylase gene (MgCYP51) in Mycosphaerella graminicola isolates confers a novel azole fungicide sensitivity phenotype. Pest Manag Sci 68: 1034-1040.

Cools, H.J., Fraaije, B.A., Kim, S.H., and Lucas, J.A., 2006. Impact of changes in the target P450 CYP51 enzyme associated with altered triazole-sensitivity in fungal pathogens of cereal crops. Biochem Soc Trans 34: 1219-1222.

Cools H.J., Fraaije B.A., Bean, T.P., Antoniw, J. and Lucas, J.A. 2007. Transcriptome profiling of the response of Mycosphaerella graminicola isolates to an azole fungicide using cDNA microarrays. Mol Plant Pathol 8: 639-651.

Cox, K. D., Quello, K., Deford, R. J., and Beckerman, J. L. 2009. A rapid method to quantify fungicide sensitivity in the brown rot pathogen Monilinia fructicola. Plant Dis. 93:328331.

Cox K.D., Bryson P.K. and Schnabel G. 2007. Instability of propiconazole resistance and fitness in Monilinia fructicola. Phytopathology 97:448-453

Cunha, M.G., Rizzo, D.M., 2003. Development of fungicide cross resistance in Helminthosporium solani population from California. Plant Dis. 87, 798-803.

Del Sorbo, G., Schoenbeck, H.-J. and De Waard, M.A. 2000: Fungal transporters involved in efflux of natural toxic compounds and fungicides. Fungal Genet. Biol. 30, 1-15.

Delye, C., Laigret, F. and Corio-Costet, M.F.1997 A mutation in the $14 \alpha$-demethylase gene of Uncinula necator that correlates with resistance to a sterol biosynthesis inhibitor. Appl Environ. Microbiol. 63:2966-2970.

Delye C., Bousset L. and Corio-Costet M.F.1998. PCR cloning and detection of point


hordei, a 'recalcitrant' fungus. Curr Genet 34:399-403.

Detweiler, A.R., Vargas, J.M. and Danneberger, T.K. 1983. Resistance of Sclerotinia homoeocarpa to iprodione and benomyl. Plant Dis. 67:627-30.

de Waard, M., Andrade, A. C. Hayashi, K. , Schoonbeek, H., Stergiopoulos, I. and Zwiers, L. 2006. Impact of fungal drug transporters on fungicide sensitivity, multidrug resistance and virulence. Pest Manag. Sci. 62:195-207.

Dunbar, S. A. 2006. Applications of Luminex xMAP technology for rapid, high-throughput multiplexed nucleic acid detection. Clin. Chim. Acta 363:71-82.

Dyer, P. S., J. Hansen, A. Delaney, and Lucas, J. A. 2000. Genetic control of resistance to the sterol $14 \alpha$-demethylase inhibitor fungicide prochloraz in the cereal eyespot pathogen Tapesia yallundae. Appl. Environ. Microbiol. 66:4599-4604 
Faretra, F. and Pollastro, S. 1993. Isolation, characterization and genetic analysis of laboratory mutants of Botryotinia fuckeliana resistant to the phenylpyrrole fungicide. Mycol. Res. 97: 620-624.

Fraaije B.A., Cools H.J., Kim S-H, Motteram J, Clark, W.S. and Lucas J.A. 2007. A novel substitution I381V in the sterol 14 $\alpha$-demethylase (CYP51) of Mycosphaerella graminicola is differentially selected by azole fungicides. Mol Plant Pathol 8: 245-254

Fraaije, B.A., Butters, J.A.. J.M. Coehlo, D.R. Jones and Hollemon, D.W. 2002: Following the dynamics of strobilurin resistance in Blumeria graminis $f$. sp. tritici using quantitative allele-specific real-time PCR measurements with the fluorescent dye SYBR Green I. Plant Pathol. 51:45-54.

Fontaine, A., Remuson, F., Fraissinet-Techet, L., Micoud, A., Marmeisse, R., and Melayah, D. 2009. Monitoring of Venturia inaequalis harboring the QoI resistance G143A mutation in French orchards as revealed by PCR assays. Pest Manag. Sci. 65:74-81.

FRAC, 2006. Mutations associated with QoI resistance. Available on line at http://frac.info/frac/work/Mutations\%20associated\%20with\%20QoI\%20resistance.pdf. Accessed 9/4/2012.

Frac, 2009. FRAC Code List: Fungicides sorted by mode of action (including FRAC Code numbering) http://www.frac.info/frac/publication/anhang/FRAC_CODE_LIST.pdf

Fujimura M., Chiai, N., Ichiishi, A., Usami, R., Horikoshi, K., and Yamaguchi, I. 2000. Sensitivity to phenylpyrrole fungicides and abnormal glycerol accumulation in Os and Cut mutant strains of Neurospora crassa. J. Pestic. Sci., 25: 31-36

Genet J.L., Jaworska, G. and Deparis, F.2006. Effect of dose rate and mixtures of fungicides on selection for QoI resistance in populations of Plasmopara viticola. Pest Manag Sci 62: 188-194.

Grindle, M. 1982. Fungicide-resistance of os mutants of Neurospora crassa. Neurospora Newslett., 29:16-17.

Grube, A., Donaldson, D., Kiely, T., and Wu, L. 2011. Pesticide industry sales and usage. 2007 market estimates. 34 pp. Available at:

http://www.epa.gov/opp00001/pestsales/07pestsales/market_estimates2007.pdf Last accessed 3/12/2012.

Hamamoto, H., Hasegawa, K., Nakaune, R., Lee, Y. J., Makizumi, Y., Akutsu, K., and Hibi, T. 2000. Tandem repeat of a transcriptional enhancer upstream of the sterol 14 alphademethylase gene (CYP51A1) in Penicillium digitatum. Appl. Environ. Microbiol. 66:3421-3426.

Hayashi, H., Schoonbeek, M.A. and De Waard, M. 2002. Expression of the ABC transporter BcatrD from Botrytis cinerea reduces sensitivity to sterol demethylation inhibitor fungicides. Pestic. Biochem. Physiol. 73:110-121.

Higgins C F. 1992. ABC transporters: from microorganisms to man. Annu Rev. Cell. Biol. 8:67-113.

Hilber, U. W., and Hilber-Bodmer, M. 1998. Genetic basis and monitoring of resistance of Botryotinia fuckeliana to anilinopyrimidines. Plant Dis. 82:496-500.

Ikuta S., Takagi K., Wallace, R.B., and Itakura, K. 1987. Dissociation kinetics of 19 base paired oligonucleotide-DNA duplexes containing different single mismatched base pairs. Nucleic Acids Res. 15:797-811. 
Ishii, H., Yano, K., Date, H., Furuta, A., Sagehashi, Y., Yamaguchi, T., Sugiyama, T., Nishimura, K., and Hasama, W. 2007. Molecular characterization and diagnosis of QoI resistance in cucumber and eggplant fungal pathogens. Phytopathology 97:1458-1466.

Ishii H., Fountaine, J., Chung, W-H, Kansako, M., Nishimura, K., Takahashi, K., and Oshima, M. 2009. Characterisation of QoI-resistant and field isolates of Botrytis cinerea from citrus and strawberry. Pest Manag Sci 65: 916-922.

Ito, Y., , Muraguchi, H., Seshime, Y., Oita, S. and Yanagi, S.O. 2004 Flutolanil and carboxin resistance in Coprinus cinereus conferred by a mutation in the cytochrome b560 subunit of succinate dehydrogenase complex (Complex II) Mol. Genet. Genomics 272 :328-335.

Kawchuk, L.M., Hutchison, L.J., Verhaeghe, C.A., Lynch, D.R., Bains, P.S., and Holley. J.D. 2002. Isolation of the $\beta$-tubulin gene and characterization of thiabendazole resistance in Gibberella pulicaris. Can. J. Plant Pathol. 24: 233-238

King, J.E. and Griffin, M.J. 1985.Survey of benomyl resistance in Pseudocercosporella herpotrichoides on winter wheat and barley in England and Wales in 1983. Plant Pathology 34: 272-83.

Koenraadt, H., and Jones, A. L. 1992a. The use of allele-specific oligonucleotide probes to characterization resistance to benomyl in field strains of Venturia inaequalis. Phytopathology 82:1354-1358.

Koenraadt, H., Somerville, S. C., and Jones, A. L. 1992b. Characterization of mutations in the beta-tubulin gene of benomyl-resistant field strains of Venturia inaequalis and other plant pathogenic fungi. Phytopathology 82:1348- 1354.

Köller, W., Wilcox, W. F., Barnard, J., Jones, A. L., and Braun, P. G. 1997. Detection and quantification of resistance of Venturia inaequalis populations to sterol demethylation inhibitors. Phytopathology 87:184-190.

Köller, W., and Wilcox, W. F. 2001. Evidence for the predisposition of fungicide-resistant phenotypes of Venturia inaequalis to a preferential selection for resistance to other fungicides. Phytopathology 91:776-781.

Köller, W., Parker, D. M., and Reynolds, K. L. 1991. Baseline sensitivities of Venturia inaequalis to sterol demethylation inhibitors. Plant Dis. 75:726-728.

Kretschmer M, Leroch M, Mosbach A, Walker A-S, Fillinger S, Mernke D, et al. 2009. Fungicide-driven evolution and molecular basis of multidrug resistance in field populations of the grey mould fungus Botrytis cinerea. PLoS Pathogens 5: 1-13.

Kuhn P.J. 1984. Mode of action of carboximides. Symp. Ser. Br. Mycol. Soc., 9:155-183.

Latin, R.X. 2011. A practical guide to turfgrass fungicides. The American Phytopathological Society, $270 \mathrm{pp}$.

Leroux,P. Gredt,M., Remuson, F., Micoud, A., Walker, A-S. 2013. Fungicide resistance status in French populations of the wheat eyespot fungi Oculimacula acuformis and Oculimacula yallundae. Pest. Manag. Sci .69:15-26.

Leroux P and Walker A-S. 2011. Multiple mechanisms account for resistance to sterol 14 $\alpha$ demethylation inhibitors in field isolates of Mycosphaerella graminicola. Pest. Manag. Sci. 67: 44-59.

Leroux P, Gredt M, Leroch M, Walker AS. 2010. Exploring mechanisms of resistance to respiratory inhibitors in field strains of Botrytis cinerea, the causal agent of gray mold. App. Environ. Microbiol. 76:6615-6630. 
Leroux P, Albertini C, Gautier A, Gredt M and Walker AS. 2007. Mutations in the cyp51 gene correlated with changes in sensitivity to sterol $14 \alpha$-demethylation inhibitors in field isolates of Mycosphaerella graminicola. Pest. Manag. Sci. 63: 688-699.

Leroux P, Chapeland F, Desbrosses D and Gredt M. 1999. Patterns of cross-resistance to fungicides in Botryotinia fuckeliana (Botrytis cinerea) isolates from French vineyards. Crop Protect 18:687-697.

Leroux, P., Lanen, C., and Fritz, R. 1992. Similarities in the antifungal activities of fenpiclonil, iprodione and tolclofos-methyl against Botrytis cinerea and Fusarium nivale. Pestic. Sci. 36, 325-329.

Leroux, P. and Gredt, M., 1989. Negative cross-resistance of benzimidazole-resistant strains of Botrytis cinerea, Fusarium nivale and Pseudocercosporella herpotrichoides to various pesticides. Netherlands J. Plant Pathol. 95:121-127.

Lesemann, S.S., Schimpke, S., Dunemann, F. and Deising H.B. 2007. Mitochondrial heteroplasmy for the cytochrome $b$ gene controls the levels of strobilurin resistance in the apple powdery mildew fungus Podosphaera leucotricha (Ell. \& Ev.) E.S. Salmon. J Plant Dis Protect 113: 259-266.

Lesniak, K. E., Proffer, T. J., Beckerman, J. L., and Sundin, G. W. 2011. Occurrence of QoI resistance and detection of the G143A mutation in Michigan populations of Venturia inaequalis. Plant Dis. 95:927-934.

Luo, C.-X., Cox, K. D., Amiri, A., and Schnabel, G. 2008. Occurrence and detection of the DMI resistance-associated genetic element 'Mona' in Monilinia fructicola. Plant Dis. 92:1099-1103.

Luminex website: http://www.luminexcorp.com/TechnologiesScience/xMAPTechnology/ accessed 10/22/2012.

Lyr, H. 1977. Effects of fungicides on energy production and intermediary metabolism, p. 301-332. In M. Siegel and H. D. Sisler (ed.), Antifungal compounds. Volume 2: interactions in biological and ecological systems. Dekker M, New York, NY.

Ma, Z., and Michailides, T. 2005. Advances in understanding molecular mechanisms of fungicide resistance and molecular detection of resistant genotype in phytopathogenic fungi. Crop Prot. 24:853-863.

Ma, Z., T. J. Proffer, J. L. Jacobs, and G. W. Sundin. 2006. Overexpression of the 14 alphademethylase target gene (CYP51) mediates fungicide resistance in Blumeriella jaapii. Appl. Environ. Microbiol. 72:2581-2585.

Mann, M. and Jensen, O. N. 2003. Proteomic analysis of post-translational modifications. Nat. Biotechnol. 21: 255-261.

Mernke, D., Dahm, S., Walker, A.-S., Lalève, A., Fillinger, S., Leroch, M., and Hahn, M. 2011. Two promoter rearrangements in a drug efflux transporter gene are responsible for the appearance and spread of multi- drug resistance phenotype MDR2 in Botrytis cinerea isolates in French and German vineyards. Phytopathology 101:1176-1183.

Metzker ML 2010. Sequencing technologies-the next generation. Nature Rev.Gen. 11:31-46.

Miguez, M. Reeve, C., Wood, P., and Hollomon, D. 2003. Alternative oxidase reduces the sensitivity of Mycosphaerella graminicola to QoI fungicides. Pest. Manag. Sci. 60:3-7.

Nakaune, R., Adachi, K., Nawata, O., Tomiyama, M., Akutsu, K., and Hibi, T. 1998. A novel ATP-binding cassette transporter involved in multidrug resistance in the phytopathogenic fungus Penicillium digitatum. Appl Environ Microbiol 64: 3983-3988. 
Nurmi J., Ylikoski, A., Soukka, T., Karp, M., and Lövgren, T. 2000. A new label technology for the detection of specific polymerase chain reaction products in a closed tube. Nucleic Acids Res 15:28:e28

Ochiai, N., Fujimura, M., Motoyama, T., Ichiishi, A., Usami, R., Horijoshi, K., Yamaguchi, I., 2002. Characterization of mutations in the two-component histidine kinase gene that confer fludioxonil resistance and somotic sensitivity in the os-1 mutants of Neurospora crassa. Pest Manag. Sci. 57, 437-442.

Orth, A.B., Rzhetskaya, M., Pell, E.J., Tien, M., 1995. A serine (threonine) protein kinase confers fungicide resistance in the phytopathogenic fungus Ustilago maydis. Appl. Environ. Microbiol. 61: 2341-2345.

Orth, A.B., Sfarra, A., Pell, E.J., and Tien, M., 1994. Characterization and genetic analysis of laboratory mutants of Ustilago maydis resistant to dicarboximide and aromatic hydrocarbon fungicides. Phytopathology 84: 1210-1214.

Oshima, M., S. Banno, K. Okada, T. Takeuchi, M. Kimura, A. Ichiishi, I. Yamaguchi, M. Fujimura. 2006. Survey of mutations of a histidine kinase gene BcOS1 in dicarboximideresistant field isolates of Botrytis cinerea J. Gen. Plant Path. 72: 65-73

Oshima, M., Fujimura, M., Banno, S., Hashimoto, C., Motoyama, T., Ichiishi, A., and Yamaguchi, I. 2002. A point mutation in the two component histidine kinase BcOS-1 gene confers dicarboximide resistance in field isolates of Botrytis cinerea. Phytopathology 92:75-80.

Pao, S. S., Paulsen, I. T., and Saier, M. H., Jr. 1998. Major facilitator superfamily. Microbiol. Mol. Biol. Rev. 62: 1-34.

Pasche, J.S., Piche, L.M., Gudmestad, N.C., 2005. Effect of the F129L mutation in Alternaria solani on fungicides affecting mitochondrial respiration. Plant Dis. 89, 269-278.

Patel, J. S., Meinhardt, S. W., Sierotzki, H., Stammler, G., Gudmestad, N. C., and Adhikari, T. B. 2011. A two-step molecular detection method for Pyrenophora tritici-repentis isolates insensitive to QoI fungicides. Plant Dis. 95:1558-1564.

Petrosino, J. F., Highlander, S., Luna, R. A., Gibbs, R. A. and Versalovic, J. 2009. Metagenomic pyrosequencing and microbial identification. Clin. Chem. 55, 856-866.

Pommer, E.H. and Lorenz, G. 1982. Resistance of Botryis cinerea to dicarboximide fungicides-A literature Review. Crop. Prot. 1:221-230.

Quello, K. L., Chapman, K. S., and Beckerman, J. L. 2010. In situ detection of benzimidazole resistance in field isolates of Venturia inaequalis in Indiana. Plant Dis. 94:744-750.

Ramesh MA, Laidlaw RD, Durrenberger F, Orth AB and Kronstad JW. 2001. The cAMP signal transduction pathway mediates resistance to dicarboximide and aromatic hydrocarbon fungicides in Ustilago maydis. Fungal Genet. Biol. 32:183-193.

Rampersad, S. N. 2011. A rapid colorimetric microtiter bioassay to evaluate fungicide sensitivity among Verticillium dahliae isolates. Plant Dis. 95:248-255.

Ritchie, D.F. 1983. Mycelia growth, peach fruit-rotting, capability, and sporulation of strains of Monilinia fructicola resistant to dichloran, iprodione, procymidone, and vinclozolin. Phytopath. 73: 44-47.

Sambrook J., Fritsch E.F., Maniatis T. (1989) Molecular cloning: A laboratory manual (Cold Spring Harbor Laboratory Press, Cold Spring Harbor, NY), 2nd ed. 
Sanglard, D., K. Kuchler, F. Ischer, J. L. Pagani, M. Monod, and Bille, J. 1995. Mechanisms of resistance to azole antifungal agents in Candida albicans isolates from AIDS patients involve specific multidrug transporters. Antimicrob. Agents Chemother. 39:2378-2386.

Sanglard, D., F. Ischer, D. Calabrese, P. A. Majcherczyk, and Bille. J. 1999. The ATP binding cassette transporter gene CgCDR1 from Candida glabrata is involved in the resistance of clinical isolates to azole antifungal agents. Antimicrob. Agents Chemother. 43:27532765.

Schnabel, G., and Jones, A. L. 2001. The 14 $\alpha$ - demethylase (CYP51A1) gene is overexpressed in Venturia inaequalis strains resistant to myclobutanil. Phytopathology 91:102-110.

Schroeder, W. T., and Providenti, R. 1969. Resistance to benomyl in powdery mildew of cucurbits. Plant Dis. Rep. 53:271-275.

Sisler, H. 1988.Fungicide action and fungicide resistance mechanisms. In Fungicide Resistance in North America. Delp, C.J. Editor p.6-8.

Stammler, G. Benzinger, J. Speakman. 2007. A rapid and reliable method for monitoring the sensitivity of Sclerotinia sclerotiorum to boscalid J. Phytopathol., 155:746-748

Stammler, G and Speakman, J. 2006 Microtiter method to test the sensitivity of Botrytis cinerea to boscalid J. Phytopathol., 154 :508-510.

Stehmann, C., and De Waard, M. A. 1996. Sensitivity of populations of Botrytis cinerea to triazoles, benomyl and vinclozolin. Eur. J. Plant Pathol. 102:171-180.

Sierotzki H, Frey R and Wullschleger J, 2007.Cytochrome b gene sequence and structure of Pyrenophora teres and P. tritici-repentis and implications for QoI resistance. Pest Manag Sci 63: 225-233.

Stergiopoulos I, Van Nistelrooy, J.G.M., Kema G.H.J. and De Waard M.A. 2003. Multiple mechanisms account for variation in base-line sensitivity to azole fungicides in field isolates of Mycosphaerella graminicola. Pest Manag Sci 59: 1333-1343.

Suzuki, F., Yamaguchi, J., Koba, A., Nakajima, T., and Arai, M. 2010. Changes in fungicide resistance frequency and population structure of Pyricularia oryzae after discontinuance of MBI-D fungicides. Plant Dis. 94:329-334.

Tomlinson, J.A., I. Barker and N. Boonham. 2007. Faster, Simpler, More-Specific Methods for Improved Molecular Detection of Phytophthora ramorum in the Field. Appl. Environ. Microbiol. 73 :4040-4047.

Troy, T. 2011. Fast-Growing Fungicide Markets. Farm Chemicals International. Sept. 2011. http://www.farmchemicalsinternational.com/magazine/?storyid=3238

van den Bosch F, Pavely N, Shaw M, Hobbelen P and Oliver R. (2011). The dose rate debate: does the risk of fungicide resistance increase or decrease with dose? Plant Pathol 60: 597-606.

Villani, S. M., and Cox, K. D. 2011. Characterizing fenbuconazole and propiconazole sensitivity and prevalence of 'Mona' in isolates of Monilinia fructicola from New York. Plant Dis. 95:828-834.

Vincelli P. and Tisserat N. 2008. Nucleic acid-based pathogen detection in applied plant pathology. Plant Dis. 92:660-69.

Whitford, F., Pike, D., Burroughs, F., Hanger, G., Johnson, B., and Brassard, D. 2006. The Pesticide Marketplace: Discovering and developing new products. PPP-71. Available on-line at: http://www.ppp.purdue.edu/Pubs/ppp-71.pdf. 
Wilson, D. and Wicks, T.. 2011. FungicideResistant Powdery Mildew In Australian Vines. Available on line, http://www.cropcare.com.au/Assets/564/1/ADVivando2011FungicideResistantPowderyMildewInAustralianVines.pdf Accessed on 9/4/2012.

Wiederhold, N. P., Grabinski, J. L. Garcia-Effron, G. Perlin, D. S., and Lee, S. A. 2008. Pyrosequencing to detect mutations in FKS1 that confer reduced echinocandin susceptibility in Candida albicans. Antimicrob. Agents Chemother. 52:4145-4148.

Wood, H.M. M.J. Dickinson, J.A. Lucas, P.S. Dyer. 2001. Cloning of the CYP51 gene from the eyespot pathogen Tapesia yallundae indicates that resistance to the DMI fungicide prochloraz is not related to sequence changes in the gene encoding the target site enzymeFEMS Microbiol. Lett., 196:183-187

Wyand, R. A., and Brown, J. K. M. 2005. Sequence variation in the CYP51 gene of Blumeria graminis associated with resistance to sterol demethylase inhibiting fungicides. Fungal Genet. Biol. 42:726-735.

Yarden, O. and Katan, T. 1993. Mutation leading to substitutions at amino acids 198 and 200 of beta-tubulin that correlated with benomyl-resistance phenotypes of field strains of Botrytis cinerea. Phytopathology 83, 1478-1483.

Zhang, Y., Lamm, R., Pillonel, C., Lam, S. and Xu, J. R. 2002. Osmoregulation and fungicide resistance: the Neurospora crassa os-2 gene encodes a HOG1 mitogen-activated protein kinase homologue. Appl. Environ. Microbiol. 68:532-538.

Zheng, D., Olaya, G., and Koeller, W. 2000. Characterization of a laboratory mutant of Venturia inaequalis resistant to the strobilurin- related fungicide Kresoxim-methyl. Curr. Genet. 38:148-155.

Zhu, F., Bryson, P.K, and Schnabel, G. 2012. Influence of storage approaches on instability of propiconazole resistance in Monilinia fructicola. Pest Manag. Sci. 68:1003-1009.

Zwiers, L.H., Stergiopoulos, I., Van Nistelrooy, J.G.M., De Waard, M.A.. 2002. ABC transporters and azole susceptibility on laboratory strains of the wheat pathogen Mycosphaerella graminicola. Antimicrob. Agents Chemother.46 pp. 3900-3906. 